\title{
Corticosteroids in the management of influenza, SARS, MERS and COVID-19
}

\author{
rathnasiri bandara ${ }^{1}$ and tharuka herath ${ }^{2}$ \\ ${ }^{1}$ Affiliation not available \\ ${ }^{2}$ National Hospital of Sri Lanka
}

May 11, 2020

\begin{abstract}
Steroids treatment has been studied in influenza, SARS, MERS, COVID-19 and ARDS, but no clear guidelines or recommendations are available regarding the dose and the duration. In this review we summarize the studies available on steroids and influenza, SARS, MERS, COVID-19 and evaluated them according to the steroid dose, duration and beneficial and harmful effects. Steroids were not much useful in influenza infection, but have shown beneficial effects in SARS and COVID-19. Intimidate and high doses for a short duration in SARS is beneficial, especially if used after the viral replication phase. Methyl prednisolone is the preferred steroid compared to hydrocortisone and can be combined with intravenous immunoglobulin, ribavirin, quinolone plus azithromycin. Limited studies are available for COVID-19 and steroids to provide recommendations and steroids use can be harmful in critically ill patients. Delayed viral clearance, secondary bacterial infections, cardiovascular events due to fluid retention, psychosis, diabetes, avascular necrosis and osteoporosis can be side effects of steroid use.
\end{abstract}

\section{Hosted file}

manuscript.docx available at https://authorea.com/users/320019/articles/450204corticosteroids-in-the-management-of-influenza-sars-mers-and-covid-19 